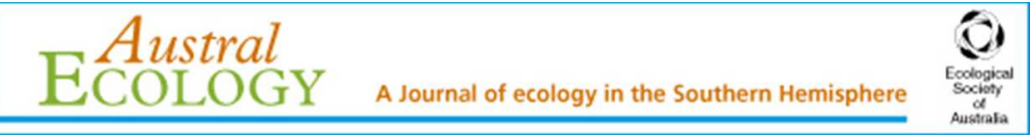

\title{
An experimental demonstration of the impact of predation on sexual segregation and primary sex ratios amongst ungulates
}

\begin{tabular}{|r|l|}
\hline Journal: & Austral Ecology \\
\hline Manuscript ID & AEC-16-028-OA.R2 \\
\hline Manuscript Type: & Original Article \\
\hline Date Submitted by the Author: & n/a \\
\hline Complete List of Authors: & $\begin{array}{l}\text { O'Kane, Christopher; University of Oxford, Zoology } \\
\text { Macdonald, David; Oxford University, Zoology Departament }\end{array}$ \\
\hline Keywords: & $\begin{array}{l}\text { bachelor herds, breeding herds, herbivores, reproductive strategy, } \\
\text { savanna, territorial }\end{array}$ \\
\hline
\end{tabular}


1 An experimental demonstration of the impact of 2 predation on sexual segregation and primary sex ratios 3 amongst ungulates

6 Christopher A.J. O'Kane ${ }^{\text {a, } 1}$ christopher.okane@zoo.ox.ac.uk

7 David W. Macdonald ${ }^{\text {a }}$ david.macdonald@zoo.ox.ac.uk

$9{ }^{a}$ Wildlife Conservation Research Unit, Department of Zoology, University of Oxford,

10 The Recanati-Kaplan Centre, Tubney House, Abingdon Road, Tubney, Oxon OX13 5QL,

11 United Kingdom.

$13{ }^{1}$ Corresponding author: address as at ${ }^{a}$, tel: +44 (0) 1865 393100, fax: +44 (0) 1865

$14 \quad 393101$

16 Running title: ungulate sexual segregation and PSR

17 Word count: all 5,950; Abstract 230; main text 4,000; acknowledgements 50; references

$18 \quad 1,600$

19 Tables: 0; figures 1; Pages: 27

20 References: 73 . 
22 Abstract

23 Underlying mechanisms of sexual segregation amongst ungulates, and Trivers and

24 Willard's hypothesis that mothers can influence primary sex ratios, continue to be topical

25 theoretical issues. Over two years, using monthly repeated road transects, we determined

26 the habitat and social segregation of male versus female impala (Aepyceros melampus)

27 and kudu (Tragelaphus strepsiceros) in a predator-free, versus a predator-laden, South

28 African reserve. We also determined, by the same technique but over four years, the

29 primary sex ratio of the impala population free from predation. Significant overlap in

30 habitat usage (Schoener's Index 0.63 to 0.8 ) was found between the two sexes when free

31 from predation, but not (Schoener's Index 0.46 to 0.47 ) when under predation. Whilst

32 occupying the same habitats impala, kudu and wildebeest (Connochaetes taurinus) male

33 and female groups maintained rigid social segregation throughout the year, even when at

34 close quarters. Impala primary sex ratios were significantly biased towards females

$35\left(\right.$ male $/$ female $=0.72 ; \chi^{2}=4.3175, \mathrm{df}=1, \mathrm{p}$-value $\left.=0.038\right)$ in the absence of predation.

36 Our findings suggest that whilst risk of predation is a proximal cause of sexual

37 segregation, thus lending support to the predator-risk hypothesis, the underlying,

38 functional mechanism of sexual segregation is difference in the activity budgets of males

39 versus females (the activity-budget hypothesis). Our findings also suggest that mothers

40 may indeed be able to adjust primary sex ratios, with the postulated driver in this case

41 being an abnormally high density of adult males.

42 
43 Key Words: bachelor herds, breeding herds, herbivores, reproductive strategy, savanna,

44 territorial

45 


\section{Introduction}

48 Sexual segregation

49 Three main hypotheses are generally discussed in the literature (Conradt 1997; Gross

50 1998; Main 1998; Main et al. 1996; Ruckstuhl and Neuhaus 2002) to explain sexual

51 segregation. The forage-selection hypothesis (Beier 1987) suggests that females will

52 select habitat based on food quality, while males should prefer high forage biomass, the

53 predator-risk (or reproductive-strategy) hypothesis (Bowyer 1984) suggests that females

54 will use relatively predator-safe habitats, while males are predicted to use habitats with

55 higher predation risk but better food quality, and the activity-budget hypothesis (Conradt

56 1998) suggests that with increasing dimorphism in body size males and females will

57 increasingly differ in the time spent in different activities.

58 The scramble competition hypothesis, forwarded as a variant of the forage-

59 selection hypothesis, implies that females graze the vegetation in high-quality forage

60 habitats too low for males to achieve sufficient forage intake rates, and males are thus

61 forced by indirect female competition into marginal habitats with lower forage quality but

62 higher forage biomass (Clutton-Brock et al. 1982; Clutton-Brock et al. 1987). This

63 'indirect-competition' hypothesis effectively extends Jarman's (1974) and Bell's (1971)

64 argument for explaining inter-specific competition between different sized herbivore

65 species to intra-specific competition between different sized sexes of the same species.

66 However, removal of female red deer (Cervus elaphus) on the Isle of Rum, Scotland did

67 not result in males increasing their use of preferred habitat as predicted by the hypothesis

68 (Conradt et al. 1999), leading researchers to conclude that sex differences in body size 
69 within a species are, in spite of theoretical considerations (Illius and Gordon 1992), not

70 large enough for the Jarman-Bell principle to apply and, consequently, the hypothesis

71 was rejected. Reviewing the literature on sexual segregation, Main et al. (1996)

72 concluded that most evidence supported the reproductive-strategy hypothesis, whilst in a

73 later and more extensive review Ruckstuhl and Neuhaus (2002) showed that there is

74 considerably more evidence supporting the activity-budget hypothesis - out of 23 studies,

7522 confirmed the predictions of the hypothesis.

76 Earlier studies often did not make clear whether they were discussing habitat

77 segregation or social segregation or both, leading to confusion in the literature over the

78 definition of sexual segregation (Main et al. 1996), with some studies discussing habitat

79 segregation between the sexes (Tierson et al. 1985) whilst others discuss sexual

80 segregation in terms of separation between sexes occupying the same habitat/area

81 (McCullough et al. 1989). It is important that the type of sexual segregation being

82 discussed is defined. Further confusion occurs over the near avoidance of the role of

83 territoriality. This is probably because most field studies on sexual segregation have been

84 carried out in northern temperate regions (Bleich 1993; Clutton-Brock et al. 1987; Main

85 and Coblentz 1990; Miquelle et al. 1992) where territoriality is confined to a short,

86 pronounced rut - sexual segregation occurring outside of the rut is thus not related to

87 territoriality. This is not the case with several prevalent African ungulates - wildebeest

88 (Connochaetes taurinus) maintain territories all year round except in the depths of winter

89 (Attwell 1977), whilst zebra (Equus burchelli), although not defending an actual territory,

90 vigorously repel other adult males from their harems all year round (Smuts 1974; 1976).

91 In such cases clearly the behaviour of the dominant male keeps the bachelor groups 
92 separate from the breeding herds and is the proximal cause of sexual segregation, whether

93 with concomitant habitat segregation (wildebeest) or without (zebra). However, once

94 territoriality stops, it is the persistence of sexual segregation, as also occurs in the

95 northern hemisphere cervids, which is the interesting puzzle.

96 Over a two year period we determined in a predator-free game reserve, Ithala

97 Game Reserve, South Africa, the habitat occupancy and social groupings of adult male

98 and female wildebeest, impala (Aepyceros melampus) and kudu (Tragelaphus

99 strepsiceros). An impala territorial male lives amongst its breeding herd all year round,

100 but vigorously excludes other adult males, which live in bachelor herds, only during the

101 pre-rut and rut (Jarman and Jarman 1973). Kudu do not show territoriality at all (Owen-

102 Smith 1984a; b; Perrin 1999), but do show habitat segregation between the sexes over the

103 calving and post-natal period (du Toit 1995). We also determined the same parameters,

104 over two years, for impala and kudu in nearby Hluhluwe-iMfolozi Park - a reserve with

105 similar habitats and climate to Ithala, but one with a full suite of predators (although few

106 wildebeest). We assess our results here in terms of the three competing hypotheses on

107 sexual segregation, noting that only the activity-budget hypothesis allows for social

108 separation without concomitant habitat segregation, whilst the predator-risk hypothesis

109 implies differing behaviour in the presence versus absence of predation.

\section{Primary sex ratios (sex ratios at birth)}

112 Fisher (1930) showed that natural selection favours those parents who invest equally in

113 their male and female offspring. Trivers and Willard (1973) later argued that, under

114 certain well defined conditions, natural selection favours deviations away from a 50/50 
115 ratio but that these deviations cancel out in the local breeding population. They

116 hypothesised that mothers in comparatively better condition would gain from a

117 reproductive strategy where they biased the production of their young towards males,

118 whilst those in a comparatively poorer condition would bias production towards females

119 - the reasoning being that the condition of the young tends to correlate with that of the

120 mother during the period of parental investment, and male offspring in superior condition

121 are reproductively more successful, due to intra-sexual competition, whilst female

122 offspring tend to reproduce whatever their condition. At the time Trivers and Willard

123 hypothesised that such a bias might be effected by the female adjusting either the birth

124 sex ratio or maternal investment after birth. In ungulates evidence for the former is

125 equivocal and, rather, supports the latter (Hewison and Gaillard 1999). Recent results

126 from the long-term study of red deer on the Isle of Rum, Scotland suggest that even post-

127 weaning maternal associations affect the survival of offspring (Andres et al. 2013).

128 Evidence for the Trivers and Willard hypothesis has also been put forward in relation to

129 insects (Aron 2012), birds (Alonso-Alvarez 2006) and humans (Hopcroft and Martin

130 2014; Ruckstuhl et al. 2010), although its theoretical basis continues to be questioned

131 (James 2013; Schindler et al. 2015).

132 Since, as Trivers and Willard emphasised (Hewison et al. 2002; Saltz 2001; Saltz

133 and Kotler 2003), it is not environmental conditions per se which are predicted to

134 influence the primary sex ratio but rather individual maternal condition relative to that of

135 other mothers in the population, the overall primary sex ratio of a local population should

136 be unaffected by environmental conditions and at parity. However, the Trivers and

137 Willard hypothesis requires that a mother be able to assess her condition relative to those 
138 mothers around her, so as to adopt the best reproductive strategy during that breeding

139 season. If such ability is accepted as theoretically possible, it seems reasonable to propose

140 additional abilities of mothers to assess other aspects of their local population with

141 regards to parental investment decisions. Amongst African ungulates absence of

142 predation can distort adult sex ratios, resulting in an abnormally large number of adult

143 males (Berger and Gompper 1999; Dasmann and Mossman 1962; O'Kane and Macdonald

144 2015; Vincent 1979). We propose it would benefit mothers to invest more heavily in

145 daughters if, in the absence of predators differentially reducing the number of males

146 reaching sexual maturity, considerable numbers of sons were unable to gain access (by

147 establishing territories) to reproductive females i.e. were surplus, functionally, to

148 requirements.

149 We previously determined (O'Kane and Macdonald 2015) that the adult male to

150 female ratio amongst impala, a ubiquitous African ungulate, in predator-free Ithala Game

151 Reserve is indeed unusually male heavy (adult male/female $=0.69$ ), when compared to

152 reserves with predators (e.g. Hluhluwe-iMfolozi Park $=0.43$ (O'Kane and Macdonald

153 2015), Hwange $=0.42($ Anderson 1967), Fort Tuli $=0.45($ Dasmann and Mossman

154 1962)). Over a four year period we determined the primary sex ratio of impala in Ithala

155 Game Reserve, hypothesising that the ratio would not be at par but bias towards females.

$158 \underline{\text { Methods }}$

159

160 Study areas 
161 Ithala Game Reserve $(29,653$ ha) is situated in northern KwaZulu Natal, South Africa

$162\left(27^{\circ} 30^{\prime} \mathrm{S}, 31^{\circ} 25^{\prime} \mathrm{E}\right)$. Elevation ranges from 350 to $1550 \mathrm{~m}$ a.s.l. Long-term annual rainfall

163 is $791 \mathrm{~mm}$, falling mainly during the summer (October to March). Summers are warm to

164 hot (daily average of $\left.18-30^{\circ} \mathrm{C}\right)$, with winters being warm to mild $\left(15-25^{\circ} \mathrm{C}\right)$ (Porter

165 1983). The reserve is located in steep, dissected terrain, interspersed with broad grassy

166 plains. Geology includes Archaean granite exposures, sandstones, shales and mudstones

167 of the Karoo system, and igneous dolerite dykes and sills (Porter 1983). Correspondingly,

168 soil types are as varied, although shallow, rocky (lithosols) of the Mispah form

169 predominate (Turner 1980). The vegetation is a mix of Zululand central bushveld at mid-

170 elevations and Zululand lowveld bushveld at low elevations (Low and Rebelo 1996).

171 Structurally it is a mosaic of grasslands, open savanna dominated by Acacias and more or 172 less closed thickets of broad-leaved shrubs and trees.

173 Indigenous animal populations had largely been destroyed by the 1950's in the

174 reserve by a mixture of farming (since 1884), a rinderpest epidemic (1896) and hunting,

175 including that to control tsetse fly (1919-1950) (Johnson 1990). The Natal Parks Board

176 purchased the land in 1972 and stocked it with indigenous mammals typical of the south-

177 eastern African savanna, including warthog (Phacochoerus aethiopicus), impala, black

178 (Diceros bicornis) and white rhinoceros (Ceratotherium simum), zebra (Equus burchelli),

179 buffalo (Syncerus caffer), wildebeest, kudu, giraffe (Giraffa camelopardalis) and

180 elephant (Loxodonta africana). The reserve is entirely fenced except to the north where

181 animal movement is limited by the substantial Pongola River. Consequently no

182 significant immigration/emigration of animals occurs. The reserve does not contain (and

183 has not since foundation) any large mammalian predators and carries moderate densities 
184 of impala $\left(10 \mathrm{~km}^{-2}\right)$, but high densities of wildebeest $\left(6 \mathrm{~km}^{-2}\right)$ and zebra $\left(5.6 \mathrm{~km}^{-2}\right)$

185 (O'Kane et al. 2014).

186 Hluhluwe-iMfolozi Park $\left(900 \mathrm{~km}^{2}\right)\left(28^{\circ} 00^{\prime}-28^{\circ} 26^{\prime} \mathrm{S}, 31^{\circ} 43^{\prime}-32^{\circ} 09^{\prime} \mathrm{E}\right)$ is situated

187 some $70 \mathrm{kms}$ from Ithala. It is completely fenced, with altitude ranging from $450 \mathrm{~m}$ to 60

188 m a.s.1. In iMfolozi, the section favoured by impala and kudu (O'Kane et al. 2013), long-

189 term annual rainfall is $635 \mathrm{~mm}$ and vegetation consists mainly of Zululand lowveld

190 bushveld (Mucina and Rutherford 2006), characterised by fine-leaved Acacia savanna

191 with a continuous grass layer and a fairly open tree canopy. Soils are similar to those

192 found in Ithala. The reserve carries a full suite of megaherbivores (elephant, rhino and

193 giraffe) and mesoherbivores (impala, kudu, nyala, wildebeest, zebra) and considerable

194 numbers of mammalian predators (lion, hyaena, cheetah, leopard and wild dogs). Impala

195 exist at a high density of $26 \mathrm{~km}^{-2}$ (K.Z.N.Wildlife 2008).

\section{Data collection}

198 In Ithala Game Reserve and Hluhluwe-iMfolozi Park for two years (encompassing two

199 wet and dry seasons) monthly, over a six day period, road transects covering a

200 representative sample of the reserve's different vegetation types were carried out by the

201 same observer. Transects were driven at the same time during each field trip, with

202 midday avoided. Once within a classifiable distance $(<50 \mathrm{~m}$, using binoculars $)$ with an

203 unobstructed view of the individual/group of herbivores, the number (recording rapidly

204 left to right) of wildebeest, impala and kudu, their age, sex and habitat occupancy were

205 determined. The route of the chosen transects was such that animals counted on one

206 transect would not have had time to move to another transect - thus double counting of 
207 animals was unlikely. The precise criteria for age and sex classification are as in Brooks

208 (1985); habitats were classified according to Balcomb (1996). The vegetation

209 communities, or habitat types, may be described in more detail as follows, with plant

210 nomenclature after Pooley (2003): (1) riverine and scree forest (continuous, riverine

211 vegetation), (2) wetlands (sparse, wetland vegetation), (3) undulating tall grassland

212 (sparse, old croplands not on flood plain, dominated by Hyparrhenia and Hyperthelia sp.

213 with smaller areas of increaser grass species dominated by Themeda triandra; where

214 woody species are present these include Dichrostachya cinerea, Rhus lucida and Acacia

215 nilotica), (4) basin bushveld and thicket (closed, Euclea racemosa, D. cinerea, A.

216 nilotica, Faurea saligna, Euphorbia ingens - sparse $F$. saligna and E. ingens $<2.5 \mathrm{~m}$ in

217 height), (5) mixed thornveld (ranges from open, through continuous to closed; disturbed

218 lands, often old kraal sites, A. nilotica, Aloe marlothii, Maytenus heterophylla and

219 Dombeya rotundifolia), (6) sparsely wooded hill slopes (open, Combretum apiculatum,

220 D. rotundifolia, M. heterophylla, A. nilotica - C. apiculatum seldom found at heights <

$2212.5 \mathrm{~m}$ ), (7) tall deciduous woodland (closed, Acacia nigrescens, A. tortilis, A. robusta,

222 Spirostachys africana, Maytenus senegalensis), (8) woody rocky outcrops (ranges from

223 open to closed; patchy unit composed of grassland with granite outcrops on which woody

224 species found include Terminalia phanerophlebia, Sclerocarya birrea subsp. caffra, A.

225 nilotica, Lannea discolor).

226 Impala are seasonal breeders and, as previously observed (Brooks 1985), lamb in

227 Ithala Game Reserve over a few weeks in November and December. Although only male

228 impala carry horns, the window of opportunity for confidently assigning sex to all

229 juveniles is small. In the months immediately following birth horn buds in the males, 
230 once they appear, are only seen close up (leading to a bias in recorded males as this is the

231 only sex one can, when occasionally close enough, assign), and by May female juveniles,

232 due to their almost equal size, are difficult to distinguish from yearling females. Thus the

233 sex of impala juveniles in Ithala Game Reserve was recorded only over March and April,

234 with data being gathered over a four year period by the road transect method described

235 above. By restricting the determination of impala juveniles' sex to these two months,

236 virtually all $(>95 \%)$ juveniles spotted within the classifiable distance $(<50 \mathrm{~m}$, using

237 binoculars) were sexed.

238

239 Data analysis

240 For impala we compared habitat usage of breeding herds versus bachelor herds over the

241 period June to February (thus excluding the territorial pre-rut/rut period of March to

242 April). For kudu we compared adult female versus adult male habitat usage over the

243 calving/post-natal period of March to July with the rest of the year (August to February).

244 For both species we then compared our findings in predator-free Ithala Game Reserve

245 versus those in predator-heavy Hluhluwe-iMfolozi Park. Percentage overlap is the

246 simplest measure of niche overlap to interpret because it is a measure of the actual area of

247 overlap of the resource utilization curves (Krebs 1999). We assessed overlap in habitat

248 usage between pairs of social groupings of a herbivore species using Schoener's index

249 (Schoener 1970), recommended by Abrams (1980) as the best of the measures of niche

250 overlap (Krebs 1999). Where there is no use of the same resources this index is zero, and

251 where completely identical resources are used it is one; overlap is significant where the

252 index $\geq 0.6$ (Wallace 1981). Schoener's index for overlap of habitat usage was: 
$253 \quad S_{a b}=1-\frac{1}{2} \sum_{i=1}^{n}\left|p_{a i}-p_{b i}\right|$

254 where $S_{a b}=$ Schoener's index for overlap of habitat usage between social groupings $a$ and

$255 b$ of a species, $p_{a i}=$ proportion of the overall habitat usage that usage of habitat type $i$ by

256 social grouping $a$ forms, $p_{b i}=$ similarly for social grouping $b, n=$ number of habitat

257 types. Although Schoener's index is relatively unaffected by sample size (Krebs 1999),

258 too few wildebeest were recorded in Hluhluwe-iMfolozi Park for analysis. We also

259 assessed differences in the proportion of breeding herds/females occupying habitat types

260 not occupied by bachelor herds/males, between reserves or at different times of year, by

261 applying Pearson's chi-square test with Yates' continuity correction (Crawley 2005).

262 In southern Africa juvenile impala of both sexes remain within their natal herd

263 throughout the first year of life (Jarman and Jarman 1973; Murray 1982). We assumed

264 there is no significant difference in their mortality while both sexes remain within the

265 herd, and that therefore the juvenile sex ratio recorded over March and April equals the

266 primary sex ratio. We tested for significance $(\mathrm{P}<0.05)$ of departures from parity in the

267 primary sex ratio by applying Pearson's chi-square test with Yates' continuity correction,

268 carried out in S-PLUS (MathSoft 1999).

269

270

271 Results

272

273 Sexual segregation 
Wildebeest Ithala Game Reserve. The majority of wildebeest territorial males

275 abandoned their territories over the height of the dry season, moving to join the breeding

276 herds which were principally located on flushes of grass induced by winter burning. Over

277 this period bachelor herds of wildebeest also joined the breeding herds on the grass

278 flushes, but remained socially segregated from the females (Fig. 1).

279 Impala Ithala Game Reserve vs Hluhluwe-iMfolozi Park. Impala bachelor herds

280 remained socially segregated from breeding herds throughout the year in both reserves.

281 Even in the depths of winter when bachelors were observed to associate more closely

282 with breeding herds, they maintained their group cohesion and were still clearly separate

283 from the breeding females. Outside of the pre-rut/rut period, in both Hluhluwe-iMfolozi

284 Park and Ithala Game Reserve a small proportion ( 2\%) of breeding herd females was

285 seen to occupy habitat types not occupied by bachelor herds, with no significant

286 difference $\left(\chi^{2}=1.893, \mathrm{df}=1, \mathrm{p}\right.$-value $\left.=0.1689\right)$ between the two reserves. However

287 during this period whilst there was a highly significant overlap (Schoener's index $=0.8$ )

288 in habitat usage between breeding and bachelor herds in predator-free Ithala Game

289 Reserve, there was no significant overlap (Schoener's index $=0.47$ ) between the two

290 groups in Hluhluwe-iMfolozi Park.

$291 \quad K u d u$ Ithala Game Reserve vs Hluhluwe-iMfolozi Park. Outside of the rut, adult

292 male kudu maintained social segregation from adult females in both reserves. In predator-

293 free Ithala Game Reserve, the proportion of adult female kudu observed in habitat types

294 in which adult males were not observed was very low $(0.5 \%$ to $2 \%)$, and there was no

295 significant $\left(\chi^{2}=0.1358, \mathrm{df}=1, \mathrm{p}\right.$-value $\left.=0.7125\right)$ difference in these proportions

296 comparing the calving/post-natal period with the rest of the year. Additionally, 
297 Schoener's Index revealed significant and similar degrees of overlap in habitat utilisation

298 between adult male and female kudu when comparing the calving/post-natal period

299 (Schoener's index $=0.64)$ with the rest of the year $($ Schoener's index $=0.68)$. However in

300 Hluhluwe-iMfolozi Park, containing a full suite of predators, the proportion of adult

301 female kudu observed in habitat types in which adult males were not observed was

302 considerably higher (54\% calving/post-natal period; $25 \%$ rest of the year), and there was

303 a highly significant $\left(\chi^{2}=11.6104, \mathrm{df}=1, \mathrm{p}\right.$-value $\left.=0.0007\right)$ difference in these

304 proportions between the two periods. Moreover, there was no significant overlap in

305 habitat utilisation between adult male and female kudu during the calving/post-natal

306 period (Schoener's index $=0.46)$, whilst overlap was significant (Schoener's index $=$

3070.63 ) over the rest of the year.

308

309 Primary sex ratios

310 We recorded more female than male impala juveniles, over the months of March and

311 April, in each of the four years of the study (Year 1, female:male 26:22; Y2, 58:44; Y3,

$31233: 21 ; \mathrm{Y} 4,81: 55)$. Overall, the number of female to male impala juveniles significantly

313 departed from parity and was biased towards females (male/female $=0.72 ; \chi^{2}=4.3175$,

$314 \mathrm{df}=1, \mathrm{p}$-value $=0.038)$.

315

316

317 Discussion

318

319 Sexual segregation 
320 Attwell (1977), studying wildebeest in Hluhluwe-iMfolozi Park, also reported, as we

321 found in Ithala Game Reserve, that when territorial bulls were not enforcing habitat

322 segregation bachelor wildebeest joined the breeding herds on favoured grazing lawns, but

323 maintained social segregation. Anderson (1972) recorded in Hluhluwe-iMfolozi Park that

324 after territorial behaviour had declined (i.e. outside of the rut) impala bachelor herds

325 maintained habitat segregation. Jarman (1972), working in the (predator-laden) middle

326 Zambezi Valley, also recorded differential habitat selection by male versus female impala

327 outside of the rut. Our findings in Hluhluwe-iMfolozi Park were similar but contrasted

328 sharply with our findings in predator-free Ithala Game Reserve where, although social

329 segregation was maintained throughout the year, we found extensive overlap in habitat

330 usage between bachelor and breeding herds outside of the rut. Du Toit (1995), working in

331 the Kruger, showed that whilst male and female kudu live in the same habitat during

332 winter, over the calving and post-natal period they show habitat segregation, arguing that

333 this results from females occupying habitats where their calves are less at risk from

334 predation. Our results support du Toit's findings and argument, as in predator-laden

335 Hluhluwe-iMfolozi Park kudu males showed significant habitat overlap with females

336 outside of, but not during, the calving and post-natal period, whilst in predator-free Ithala

337 Game Reserve the two groups showed significant and similar degrees of habitat overlap

338 over both periods (i.e. the entire year). Perrin (1999) also reported the year round (apart

339 from over the rut) social segregation between male and female kudu that we observed in

340 both reserves.

341 Blumstein (2002) discussed antipredator behaviour and its retention/loss overtime

342 in the absence of predation, arguing that costly antipredator behaviour should be lost if it 
343 is no longer beneficial. He observed that visual predator recognition is strongly retained

344 despite no exposure to predators, but that other behaviours (e.g. flight distance) are less

345 'hard wired' and are reduced over time in the absence of predators. Avoidance of habitats

346 potentially carrying higher predation risk appears to be an example of a behavioural

347 pattern rapidly discarded without exposure to predation. It would also be in accordance

348 with various correlational studies (Greenwood 1980; Switzer 1995; 1997) that have

349 shown that an individual's past reproductive success often increases its breeding site

350 fidelity, suggesting that individuals use their reproductive experience to assess habitat

351 quality. A mooted introduction of large predators into Ithala Game Reserve may provide

352 a natural experiment in how quickly antipredator behaviour is reacquired, as well as

353 providing further correlative evidence on the proximal role of predation in sexual 354 segregation.

355 Our results thus suggest that when territorial behaviour no longer applies,

356 predatory pressures may maintain habitat segregation between adult male and female

357 ungulates, but where predation is absent, as in Ithala Game Reserve, although the two

358 groups then demonstrate considerably less habitat segregation they rigidly maintain social

359 segregation. Of the three hypotheses outlined in the introduction, only the activity-budget

360 hypothesis allows for sexual segregation without concomitant habitat segregation. An

361 attraction of the activity-budget hypothesis is that it provides a convincing functional

362 explanation for the persistence of bachelor groups even when bachelors are not forced to

363 remain as such - namely that differences in activity budgets would increase the costs of

364 synchrony necessary to maintain group cohesion in a mixed sex group (Aivaz and

365 Ruckstuhl 2011). Differing activity budgets are the most likely cause of sexual 
366 segregation across a range of species (e.g. bats, Levin et al. 2013; penguins, Ludynia et

367 al. 2013; and monkeys, Hartwell et al. 2014), whilst sexual segregation has been reported

368 amongst monomorphic birds (Hedd et al. 2014) and monomorphic fish (Griffiths et al.

369 2014). Main et al (1996) observed that the universal nature of sexual segregation among

370 polygynous ungulates suggests this behaviour is the product of selective pressures from a

371 similar evolutionary background and, moreover, that it would be more profitable to

372 understand sexual segregation in terms of selective pressures that influence reproductive

373 success across taxa, rather than to concentrate solely on separate species- or site-specific

374 explanations. The varied causes of sexual segregation that our data point to reinforce

375 Ruckstuhl's (2007) observation that different factors need to be integrated to successfully

376 describe proximal and ultimate causes of sexual segregation. Furthermore, possible

377 influences on sexual segregation other than the principal hypotheses assessed and

378 discussed here have been variously proposed (e.g. parasite loads (Ferrari et al. 2010),

379 environmental factors (Ruckstuhl and Neuhaus 2009), reproductive status, population

380 density and sex ratios (Ruckstuhl et al. 2006)).

383 Primary sex ratios

384 Although we found a significant bias towards female juvenile impalas over the four year

385 study, it should be born in mind that as we determined the 'primary sex ratio' up to six

386 months after birth, causes other than differing maternal investment in male versus female

387 juveniles (e.g. differing susceptibility to disease or resource availability) may be

388 responsible. Nonetheless, given that in the study reserve impala juveniles of both sexes 
389 remained within their natal herds over the first year of life and that predators are absent, it

390 is difficult to envisage what these other causes realistically might be. Our findings lend

391 support to the underlying hypothesis of Trivers and Willard (1973) that mothers possess

392 the ability to influence the primary sex ratio. However Trivers and Willard specifically

393 described the situation of mothers favouring a sex dependent on their condition in

394 relation to other mothers, whilst the overall local population primary sex ratio remains at

395 parity. Our finding of an overall local population primary sex ratio bias towards one sex

396 is different, as is our postulated driver of an unnatural excess of adult males consequent

397 on their reduced mortality in the absence of predation. If such a driver exists, it would

398 presumably be effected via an endocrinal response in females related to excessive

399 territorial aggression amongst the abnormal high density of adult males. Ideally in our

400 study we would have compared the primary sex ratio in predator-free Ithala Game

401 Reserve with that in predator-laden Hluhluwe-iMfolozi Park, expecting, if our postulated

402 driver exists, to record the primary sex ratio at parity in the latter. Interestingly, Schindler

403 et al. (2015) have recently attempted to extend and generalize the Trivers-Willard theory

404 to incorporate the different life-history traits of females and males in polygynous species.

405 Arguing against our postulated driver, lack of predation may translate into

406 stronger competition amongst adult males leading to a faster turnover of territories and/or

407 smaller territories; in such a case a mother would need to continue to produce her crop of

408 sons to enter into this increased competition and would not gain from favouring more

409 daughters. Although territory size appears to decrease with increasing overall population

410 density (Estes 1997), there appear to be no analyses in the literature of ungulate territory

411 size or time held in relation to density of adult males. 
413 Acknowledgements

414 We thank the management of Ithala Game Reserve and Hluhluwe-iMfolozi Park for

415 allowing us access to the reserves, and Bruce Page for help with planning data collection.

416 Dr. O’Kane holds the Kadas Research Fellowship at WildCRU, Department of Zoology,

417 University of Oxford and is deeply grateful to Gyongyver and Peter Kadas for their

418 support.

419

420 


\section{$421 \quad$ References}

422

423 Abrams P. (1980) Some comments on measuring niche overlap. Ecology 61, 44-9.

424 Aivaz A. N. \& Ruckstuhl K. E. (2011) Costs of behavioral synchrony as a potential

425 driver behind size-assorted grouping. Behav. Ecol. 22, 1353-63.

426 Alonso-Alvarez C. (2006) Manipulation of primary sex-ratio: an updated review. Avian

427 Poult. Biol. Rev. 17, 1-20.

428 Anderson J. L. (1967) Population structure of major ungulate species in Wankie. p. 42.

429 Unpublished report, Department of National Parks and Wildlife Management, Rhodesia.

430 Anderson J. L. (1972) Seasonal changes in the social organization and distribution of the

431 impala in Hluhluwe Game Reserve, Zululand. J. Sth. Afr. Wildl. Mgmt. Ass. 2, 16-20.

432 Andres D., Clutton-Brock T. H., Kruuk L. E. B., Pemberton J. M., Stopher K. V. \&

433 Ruckstuhl K. E. (2013) Sex differences in the consequences of maternal loss in a long-

434 lived mammal, the red deer (Cervus elaphus). Behav. Ecol. Sociobiol. 67, 1249-58.

435 Aron S. (2012) Primary sex ratio regulation by queens in ants (Formicidae) and other

436 social Hymenoptera. Myrmecol. News 17, 63-80.

437 Attwell C. A. M. (1977) Reproduction and population ecology of the blue wildebeest

438 Connochaetes taurinus taurinus in Zululand. Universtiy of Natal, Pietermaritzburg.

439 Balcomb S. (1996) Vegetation mapping and a quantitive study of the altitudinal

440 distribution of the genera Acacia, Euclea and Rhus in Itala Game Reserve, Kwazulu-

441 Natal. p. 42. Department of Grassland Science, University of Natal, Pietermaritzburg.

442 Beier, P. (1987). Sex differences in quality of white-tailed deer diets. J. Mammal. 68 , $443 \quad 323-329$.

444 Bell R. H. V. (1971) A grazing system in the Serengeti. Scient. Am. 225, 86-93. 
445 Berger J. \& Gompper M. (1999) Sex ratios in extant ungulates: products of contemporary

446 predation or past life histories? J. Mammal. 80, 1084-113.

447 Bleich V. C. (1993) Sexual segregation in desert-dwelling mountain sheep. p. 126pp.

448 University of Alaska, Fairbanks.

449 Blumstein D. T. (2002) Moving to suburbia: ontogenetic and evolutionary consequences

450 of life on predator-free islands. J. Biogeogr. 29, 685-92.

451 Bowyer, R. T. (1984). Sexual segregation in southern mule deer. J. Mammal. 65, 410452417.

453 Brooks P. M. (1985) Classification of large herbivores in Ithala Game Reserve. p. 18.

454 Natal Parks Board, Pietermaritzburg, South African.

455 Clutton-Brock T. H., Guinness F. E. \& Albon S. D. (1982) Red deer: behaviour and

456 ecology of two sexes. University of Chicago Press., Chicago.

457 Clutton-Brock T. H., Iason G. R. \& Guinness F. E. (1987) Sexual segregation and density

458 related changes in habitat use in female and male red deer (Cervus elaphus L.). J. Zool.

459 (Lond) 211, 275-89.

460 Conradt L. (1997) Causes of sex differences in habitat use in red deer (Cervus elaphus

461 L.). University of Cambridge, Cambridge.

462 Conradt L., Clutton-Brock T. H. \& Thomson D. (1999) Habitat segregation in ungulates:

463 are males forced into suboptimal foraging habitats through indirect competition by

464 females? Oecologia 119, 367-77.

465 Conradt, L. (1998). Could asynchrony in activity between the sexes cause intersexual

466 social segregation in ruminant? Proc. R. Soc. Lond. (Biol.) 265, 1359-1363.

467 Crawley M. J. (2005) Statistics: an Introduction using R. John Wiley, Chichester. 
468 Dasmann R. F. \& Mossman A. S. (1962) Population studies of impala in Southern

469 Rhodesia. J. Mammal. 43, 533-7.

470 du Toit J. D. (1995) Sexual segregation in kudu: sex differences in competitive ability, 471 predation risk or nutritional needs? S. Afr. J. Wildl. Res. 25, 127-32.

472 Estes R. D. (1997) The behavior guide to African mammals. Russel Friedman Books CC, 473 South Africa.

474 Ferrari N., Rosa R., Lanfranchi P. \& Ruckstuhl K. E. (2010) Effect of sexual segregation 475 on host-parasite interaction: Model simulation for abomasal parasite dynamics in alpine 476 ibex (Capra ibex). Int. J. Parasitol. 40, 1285-93.

477 Fisher R. A. (1930) The genetical theory of natural selection. Clarendon Press, Oxford.

478 Greenwood P. J. (1980) Mating systems, philopatry and dispersal in birds and mammals. 479 Anim. Behav. 28, 1140-62.

480 Griffiths S. W., Orpwood J. E., Ojanguren A. F., Armstrong J. D. \& Magurran A. E. 481 (2014) Sexual segregation in monomorphic minnows. Anim. Behav. 88, 7-12.

482 Gross J. E. (1998) Sexual segregation in ungulates: a comment. J. Mammal. 79, 1404-9.

483 Hartwell K. S., Notman H., Bonenfant C. \& Pavelka M. S. M. (2014) Assessing the 484 Occurrence of Sexual Segregation in Spider Monkeys (Ateles geoffroyi yucatanensis), Its 485 Mechanisms and Function. Int. J. Primatol. 35, 425-44.

486 Hedd A., Montevecchi W. A., Phillips R. A. \& Fifield D. A. (2014) Seasonal Sexual

487 Segregation by Monomorphic Sooty Shearwaters Puffinus griseus Reflects Different 488 Reproductive Roles during the Pre-Laying Period. PloS One 9.

489 Hewison A. J. \& Gaillard J.-M. (1999) Successful sons or advantaged daughters? The

490 Trivers-Willard model and sex-biased maternal investment in ungulates. Tree 14, 229-34. 
491 Hewison A. J., Gaillard J.-M. \& Festa-Bianchet M. (2002) Maternal age is not a

492 predominant determinant of progeny sex ratio variation in ungulates. Oikos 98, 334-9.

493 Hopcroft R. L. \& Martin D. O. (2014) The Primary Parental Investment in Children in

494 the Contemporary USA is Education Testing the Trivers-Willard Hypothesis of Parental

495 Investment. Human Nature-an Interdisciplinary Biosocial Perspective 25, 235-50.

496 Illius A. W. \& Gordon I. J. (1992) Modelling the nutritional ecology of ungulate

497 herbivores - evolution of body size and competitive interactions. Oecologia 89, 428-34.

498 James W. H. (2013) Evolution and the variation of mammalian sex ratios at birth:

499 Reflections on Trivers and Willard (1973). J. Theor. Biol. 334, 141-8.

500 Jarman P. J. \& Jarman M. V. (1973) Social behaviour, population structure and

501 reproductive potential in impala. E. Afr. Wildl. J. 11, 329-38.

502 Jarman P. J. (1972) Seasonal distribution of large mammal populations in the unflooded

503 Middle Zambezi Valley. J. Appl. Ecol. 9(1), 283-99.

504 Jarman P. J. (1974) The social organisation of antelope in relation to their ecology.

505 Behaviour 48, 215-67.

506 Johnson L. B. (1990) Analysing spatial and temporal phenomena using geographical

507 information systems. Landscape Ecol. 4, 31-43.

508 K.Z.N.Wildlife. (2008) Population Estimates for Hluhluwe-iMfolozi Park. KZN Wildlife,

509 Hluhluwe, South Africa.

510 Krebs J. R. (1999) Ecological methodology. Benjamin/Cummings, Menlo Park.

511 Levin E., Roll U., Dolev A., Yom-Tov Y. \& Kronfeld-Shcor N. (2013) Bats of a Gender

512 Flock Together: Sexual Segregation in a Subtropical Bat. PloS One 8. 
513 Low A. B. \& Rebelo A. G. (1996) Vegetation of South Africa, Lesotho and Swaziland.

514 Department of Environmental Affairs \& Tourism, Pretoria.

515 Ludynia K., Dehnhard N., Poisbleau M., Demongin L., Masello J. F., Voigt C. C. \&

516 Quillfeldt P. (2013) Sexual segregation in rockhopper penguins during incubation. Anim.

517 Behav. 85, 255-67.

518 Main M. B. \& Coblentz B. E. (1990) Sexual segregation among ungulates: a critique.

519 Wildlife Soc. B. 18, 204-10.

520 Main M. B. (1998) Sexual segregation in ungulates: a reply. J. Mammal. 79, 1410-5.

521 Main M. B., Weckerly F. W. \& Bleich V. C. (1996) Sexual segregation in ungulates: new

522 directions for research. J. Mammal. 77, 449-61.

523 MathSoft. (1999) S-PLUS 2000. Lucent Technologies, Inc., Murray Hill, USA.

524 McCullough D. R., Hirth D. R. \& Newhouse S. J. (1989) Resource partitioning between

525 sexes in white-tailed deer. J. Wildl. Manage. 53, 277-83.

526 Miquelle D. G., Peek J. M. \& Van Ballenberghe V. (1992) Sexual segregation in Alaskan

527 moose. Wildl. Monogr. 122, 1-57.

528 Mucina L. \& Rutherford M. C. (2006) The vegetation of South Africa, Lesotho and

529 Swaziland. South African National Biodiversity Institute, Pretoria.

530 Murray M. G. (1982) The rut of impala - aspects of seasonal mating under tropical

531 conditions. Zeitschrift Fur Tierpsychologie- J. Comp. Ethol. 59, 319-37.

532 O'Kane C. A. J. \& Macdonald D. W. (2015) An experimental demonstration that

533 predation influences antelope sex ratios and resource-associated mortality. Basic Appl.

534 Ecol. 17, 370-376. 
535 O'Kane C. A. J., Duffy K., Page B. \& Macdonald D. W. (2013) Effects of resource

536 limitation on habitat usage by the browser guild in Hluhluwe-iMfolozi Park, South

537 Africa. J. Trop. Ecol. 29, 39-47.

538 O'Kane C. A. J., Page B. \& Macdonald D. W. (2014) Differing influences of resource

539 availability on the demographics and habitat selection of wildebeest compared to impala.

$540 \quad$ J. Trop. Ecol. 30, 189-98.

541 Owen-Smith N. (1984a) Demography of greater kudu Tragelaphus strepsiceros in

542 relation to rainfall. Acta Zool. Fennica 172, 197-9.

543 Owen-Smith N. (1984b) Spatial and temporal components of the mating systems of kudu

544 bulls and red deer stags. Anim. Behav. 32, 321-32.

545 Perrin M. R. (1999) The social organisation of the greater kudu Tragelaphus strepsiceros

546 (Pallas 1766). Trop. Zool. 12, 169-208.

547 Porter R. N. (1983) The woody plant communities of Itala Nature Reserve. In: Natal

548 Parks Board, Pietermaritzburg.

549 Ruckstuhl K. E. \& Neuhaus P. (2002) Sexual segregation in ungulates: a comparative test 550 of three hypotheses. Biol. Rev. 77, 77-96.

551 Ruckstuhl K. E. \& Neuhaus P. (2009) Activity budgets and sociality in a monomorphic

552 ungulate: the African oryx (Oryx gazella). Can. J. Zool.-Revue Canadienne De Zoologie

$55387,165-74$.

554 Ruckstuhl K. E. (2007) Sexual segregation in vertebrates: proximate and ultimate causes.

555 Integr. Comp. Biology 47, 245-57.

556 Ruckstuhl K. E., Colijn G. P., Amiot V. \& Vinish E. (2010) Mother's occupation and sex 557 ratio at birth. Bmc Public Health 10. 
558 Ruckstuhl K. E., Manica A., MacColl A. D. C., Pilkington J. G. \& Clutton-Brock T. H.

559 (2006) The effects of castration, sex ratio and population density on social segregation

560 and habitat use in Soay sheep. Behav. Ecol. and Sociobiol. 59, 694-703.

561 Saltz D. \& Kotler B. P. (2003) Maternal age is a predominant determinant of progeny sex

562 ratio variation in ungulates: a reply to Hewison et al. Oikos 101, 646-8.

563 Saltz D. (2001) Sex ratio variation in ungulates: adaptation meets environmental

564 perturbation of demography. Oikos 94, 377-84.

565 Schindler S., Gaillard J. M., Gruning A., Neuhaus P., Traill L. W., Tuljapurkar S. \&

566 Coulson T. (2015) Sex-specific demography and generalization of the Trivers-Willard

567 theory. Nature 526, 249-+.

568 Schoener T. W. (1970) Nonsynchronous Spatial Overlap of Lizards in Patchy Habitats.

569 Ecology 51, 408-18.

570 Smuts G. L. (1974) Growth, reproduction and population characteristics of Burchell's

571 Zebra (Equus Burchelli Antiquorum, H. Smith, 1841) in the Kruger National Park. In:

572 Faculty of Science p. 268. University of Pretoria, Pretoria.

573 Smuts G. L. (1976) Population characteristics of Burchell's Zebra (Equus Burchelli

574 Antiquorum, H. Smith, 1841) in the Kruger National Park. S. Afr. J. Wildl. Res. 6, 99-112.

575 Switzer P. V. (1995) Influences on the site fidelity of territorial animals: theoretical and

576 empirical studies. University of California, Davis, California.

577 Switzer P. V. (1997) Past reproductive success affects future habitat selection. Behav.

578 Ecol. Sociobiol. 40, 307-12.

579 Tierson W. C., Mattfield G. F., Sage R. W. \& Behrend D. F. (1985) Seasonal movements

580 and home ranges of white-tailed deer in the Adirondacks. J. Wildl. Manage 49, 760-9. 
581 Trivers R. L. \& Willard D. E. (1973) Natural selection of parental ability to vary the sex

582 ratio of offspring. Science $\mathbf{1 7 9}, 90-2$.

583 Turner D. P. (1980) Soil survey of the central Pongola River catchment - Itala Nature

584 Reserve Planning Project. Soil and Irrigation Research Institute, Pretoria.

585 Vincent J. (1979) The population dynamics of impala Aepyceros melampus in Mkuzi

586 Game Reserve. University of Natal.

587 Wallace R. K. (1981) An assessment of diet-overlap indexes. T. Am. Fish Soc. 110, 72-6. 588 
589 Figure 1: Wildebeest bachelor herds as a percentage of the total adult wildebeest

590 population in Ithala Game Reserve. During every field period of the two year study,

591 including over the height of the dry season (July/August/September), bachelor herds were

592 observed as socially segregated from breeding herds. The total adult population of

593 wildebeest in the reserve was obtained from management's annual census, whilst the

594 crosses (first year) and triangles (second year) mark the months of the two years of data

595 collection.

596

597 
598 Figure 1

599

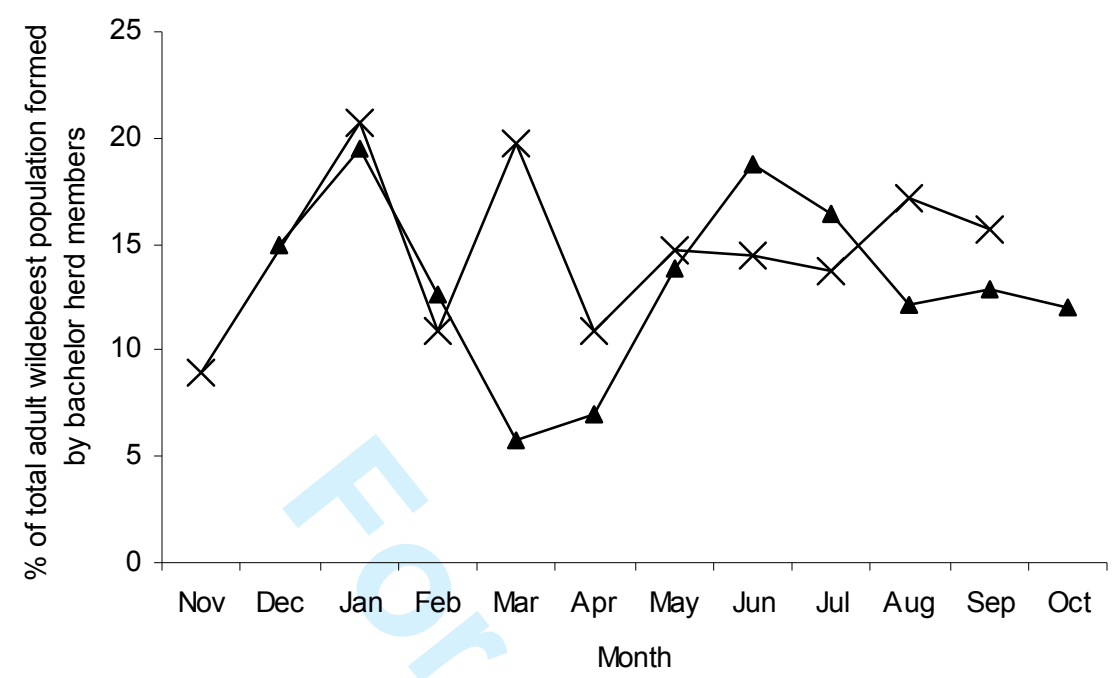

600 